smoke during pregnancy. Cord blood concentrations of biochemical markers were determined by immunoenzymatic methods and data analyses were performed using SPSS statistical software version 17.1. The study was approved by the Ethics Committee et the Institute of Mother and Child.

The newborns of smoking mothers had significantly higher concentrations of cord serum ox-LDL, TOC and GSSG $(p<0.001)$, but lower levels of GSH/GSSG ratio $(p<0.05)$ compared with newborns of non-smoking women. The levels of GSH were similar in both studied groups. Additionally, cord serum GSSG as well as TOC levels positively correlated with number of cigarettes daily consumed by the mother $(\mathrm{r}=0.49, \mathrm{r}=0.43 ; \mathrm{p}<0.05)$ and cotinine serum concentration $(\mathrm{r}=0.52, \mathrm{r}=0.43 ; \mathrm{p}<0.05)$, respectively.

Maternal smoking enhances oxidative status and depletes antioxidant potential in neonates exposed in utero to tobacco smoke. The relationship between the concentration of TOC, GSSG and the markers estimated intensity of cigarette smoking seems to confirm that the oxidant-antioxidant balance disorder in newborns is a direct result of tobacco smoke inhalation.

\section{ANTHROPOMETRICINDICATORS AND VITAMIN D LEVEL IN NEWBORNS FROM WOMEN WITH GESTATIONAL DIABETESMELLITUS}

Natalya Verisokina*, Kuryaninova Victoria, Klimov Leonid, Atanesyan Roza, Bobryshev Dmitri, Petrosyan Meline. "Stavropol State Medical University» The Ministry of Health, Stavropol, Russia

\subsection{6/archdischild-2021-europaediatrics.133}

Introduction maternal hyperglycemia during pregnancy is one of the factors of epigenetic modifications.

Objective of the study: a comparative analysis of anthropometric data and $25(\mathrm{OH}) \mathrm{D}$ level in newborns depending on the glycemic target level of the mother with GDM.

Methods 66 newborns were examined: first group - 16 (24.2\%) babies from mothers with GDM with glycemia in the III trimester of less than $5.1 \mathrm{mmol} / \mathrm{L}$; second group - 20 (30.3\%) from mothers with GDM with glycemia more than $5.1 \mathrm{mmol} / \mathrm{L}$. Control group - 30 (45.5\%) babies.

Results First and control groups: maternal glucose - 4.2 [4.04.3] $\mathrm{mmol} / \mathrm{L}$ and $4.1[3.6-4.6] \mathrm{mmol} / \mathrm{L}(\mathrm{p}>0.05)$ respectively; body weight of newborns was 3,650 [2,350-4,280] grams and $3,345[3,050-3,600]$ grams $(p>0.05)$, length 53.0 [47.0-54.0] $\mathrm{cm}$ and $51.5[50.0-53.0] \mathrm{cm}(\mathrm{p}>0.05)$, head circumference 36.0 [33.0-37.0] $\mathrm{cm}$ and $35.5[35.0-36.0] \mathrm{cm}(\mathrm{p}>0.05)$ and $25(\mathrm{OH}) \mathrm{D}$ level is $14.6[4.6-17.3] \mathrm{ng} / \mathrm{ml}$ and 14.5 [7.9-21.7] $\mathrm{ng} / \mathrm{ml}(\mathrm{p}>0.05)$ respectively.

Second group versus the control group: maternal glucose is 6.9 [5.7-7.8] $\mathrm{mmol} / \mathrm{L}(\mathrm{p}<0.001)$; weight of newborns $-3,830$ $[3,150-4,220]$ grams $(p<0.05)$; length $-53.5[50.5-55.0] \mathrm{cm}$ $(\mathrm{p}>0.05)$, head circumference $-36.0[35.0-38.0] \mathrm{cm}$ $(\mathrm{p}>0.05) ; 25(\mathrm{OH}) \mathrm{D}-6.9$ [5.7-7.8] ng/ml $(\mathrm{p}<0.05)$.

Severe deficiency of $25(\mathrm{OH}) \mathrm{D}$ in newborns from the first and second groups was detected in 5 (33.3\%) and 10 $(50.0 \%)$, deficiency - in $6(40.0 \%)$ and 7 (35.0\%), insufficiency - in $4(26.7 \%)$ and $3(15.0 \%)$ babies respectively.

Newborns from mothers with GDM with glucose more than $5.1 \mathrm{mmol} / \mathrm{L}$ had significantly higher body weight and a low level of $25(\mathrm{OH}) \mathrm{D}$ than in the control group. Babies from mothers with GDM have poorer vitamin D level than healthy newborn babies.

\section{NEONATALSEPSIS: CURRENT INFORMATION AND HOW WE ARE DOING?}

Shauna Quinn*, Daithi Kilgarrif, Noel Friesen. St John of God Midland Paediatric Department, Perth

\subsection{6/archdischild-2021-europaediatrics. 134}

Early neonatal sepsis is defined as sepsis within the first 7 days of life.

There is an incidence of $0.1-1.2 / 1000$ live births, with variation between populations. A significant reduction in GBS sepsis is recognised with introduction of intrapartum antibiotics. Predisposing risk factors include PROM, history of GBS sepsis, chorioamnionitis, prematurity and inadequate intrapartum antibiotics. The aim of this audit is to compare adequate and inadequate treatment of GBS +ve and PROM mothers and subsequent neonatal outcomes with consideration of the EOS risk calculator.

The study cohort consists of 114 neonates born at St John of God Midland between January and March. It is a retrospective review of all neonates screened during this period, with clinical data and results from Australian Clinical Labs, Infomedix and iSoft.

Of all 114 neonates screened, all were screened with a CRP and 68 with additional blood cultures. Results demonstrated one positive blood culture for S. Epidermidis, one sepsis with chorio positive growth and two presumed cases of chorioamnionitis with no growth. 50\% of those screened were treated until Mid-February, where-after there was an increase noted likely secondary to medical changeover. Amongst those screened, 66\% were empirically treated and 24\% treated following a CRP rise. We identified an issue regarding insufficient antepartum antibiotics ( $<4$ hours). 32\% of mothers were GBS +ve but only $8 \%$ received adequate antibiotics and $24 \%$ were treated inadequately.

Similarly, in PROM >18 hours only 44\% received adequate treatment despite inpatient management for $>4$ hours prior to birth. All 15 neonates born to inadequately treated mothers, were screened, two treated for CRP rises and two treated for additional risk factors.

This review highlights the importance of documentation, with inclusion of rupture of membrane and antibiotic administration times, gathering data required for the EOS calculator and liaising with the obstetric team to ensure timely administration of antibiotics. We can reduce screening and treating of neonates by optimising antepartum management or use of the EOS calculator.

\section{CHRONIC RENAL FAILURE AFTER SINGLE FETAL DEMISE IN MONOCHORIONIC TWINS - CASE REPORT}

Ana Kocijan Rebrovic*, Mirta Starcevic. University hospital centre Zagreb

\subsection{6/archdischild-2021-europaediatrics.135}

Introduction Monochorionic twins have higher rates of growth discordance, fetal loss, extreme prematurity and neonatal morbidity in general, when compared to the other types of twins. Intrauterine death of one monochorionic twin can lead to 